\title{
Anticoagulation Prescription and Outcomes in Relation to Renal Function in Patients with Atrial Fibrillation: Results from GLORIA-AF
}

\author{
Sake J. van der Wall ${ }^{1}$ Christine Teutsch ${ }^{2}$ Sergio J. Dubner ${ }^{3}$ Hans-Christoph Diener ${ }^{4}$ \\ Jonathan L. Halperin ${ }^{5}$ Chang Sheng Ma ${ }^{6}$ Kenneth J. Rothman ${ }^{7}$ Miney Paquette ${ }^{8}$ Kristina Zint ${ }^{9}$ \\ Lionel Riou França ${ }^{9}$ Shihai Lu ${ }^{10}$ Gregory Y. H. Lip ${ }^{11,12, *(\infty)}$ Menno V. Huisman ${ }^{1, *}$ on behalf of the GLORIA- \\ AF Investigators ${ }^{\#}$
}

\footnotetext{
${ }^{1}$ Department of Thrombosis and Hemostasis, Leiden University Medical Center, Leiden, The Netherlands

${ }^{2}$ Department of CardioMetabolism and Respiratory Medicine, Boehringer Ingelheim International $\mathrm{GmbH}$, Ingelheim, Germany

${ }^{3}$ Electrophysiology Service, Clínica y Maternidad Suizo Argentina, Buenos Aires, Argentina

${ }^{4}$ Faculty of Medicine, University of Duisburg-Essen, Germany

${ }^{5}$ The Cardiovascular Institute, Icahn School of Medicine at Mount Sinai, New York City, New York, United States

${ }^{6}$ Cardiology Department, Atrial Fibrillation Center, Beijing Anzhen Hospital, Capital Medical University, Beijing, China

${ }^{7}$ RTI Health Solutions, Research Triangle Institute, Research Triangle Park, North Carolina, United States

${ }^{8}$ Department of Medicine, Boehringer Ingelheim, Burlington, Ontario, Canada; Global Epidemiology at Boehringer Ingelheim $\mathrm{GmbH}$, Ingelheim, Germany
}

\author{
Address for correspondence Menno V. Huisman, MD, PhD, \\ Department of Thrombosis and Hemostasis, Leiden University \\ Medical Centre, Albinusdreef 2, 2300 RC Leiden, The Netherlands \\ (e-mail: m.v.huisman@lumc.nl).
${ }^{9}$ Global Epidemiology Department, Boehringer Ingelheim International $\mathrm{GmbH}$, Ingelheim, Germany
${ }^{10}$ Biostatistics and Data Sciences Department, Boehringer Ingelheim Pharmaceuticals, Inc., Ridgefield, Connecticut, United States
${ }^{11}$ Liverpool Centre for Cardiovascular Science, University of Liverpool and Liverpool Heart \& Chest Hospital, Liverpool, United Kingdom
${ }^{12}$ Department of Clinical Medicine, Aalborg Thrombosis Research Unit, Aalborg University, Aalborg, Denmark

TH Open 2021;5:e35-e42.

\begin{abstract}
Objective Anticoagulation management in patients with atrial fibrillation (AF) and impaired renal function is challenging. This study aimed to evaluate anticoagulation prescription patterns in relation to renal function and to describe 2-year clinical outcomes among dabigatran users.

Keywords

- atrial fibrillation

- anticoagulation

- dabigatran

- renal function

- stroke

- bleeding

Methods Global Registry on Long-Term Oral Antithrombotic Treatment in Patients with Atrial Fibrillation (GLORIA-AF) is an international, prospective, and observational study program involving patients with newly diagnosed AF at risk for stroke. Prescription patterns were assessed by creatinine clearance $(\mathrm{CrCl})$ at enrollment. Dabigatran users were followed for 2 years. Clinical outcomes were standardized for stroke and bleeding risk, based on $\mathrm{CHA}_{2} \mathrm{DS}_{2}$-VASc and HAS-BLED scores, with missing values imputed.
\end{abstract}

\footnotetext{
Joint senior authors and co-Chairs of the GLORIA-AF Registry Program.

\# For complete list of Phase II GLORIA AF Principal Investigators, please refer to the Supplementary Material.
}

received

September 2, 2020

accepted after revision

December 3, 2020
DOI https://doi.org/

$10.1055 / \mathrm{s}-0040-1722706$

ISSN 2512-9465. (c) 2021. The Author(s).

This is an open access article published by Thieme under the terms of the Creative Commons Attribution License, permitting unrestricted use, distribution, and reproduction so long as the original work is properly cited. (https://creativecommons.org/licenses/by/4.0/)

Georg Thieme Verlag KG, Rüdigerstraße 14, 70469 Stuttgart, Germany 
Results Baseline $\mathrm{CrCl}$ values were available for 12,056 of 15,308 eligible patients (79\%). With declining renal function, prescriptions increased for vitamin $\mathrm{K}$ antagonists (VKAs) and decreased for dabigatran (30-47\% and 34-12\%, respectively). The prescription of other non-vitamin $\mathrm{K}$ antagonists remained similar across $\mathrm{CrCl}$ groups (14-19\%). In 4,873 dabigatran users, standardized stroke rates were low across all $\mathrm{CrCl}$ groups; $0.58 / 100$ patient-years (95\% confidence interval $[\mathrm{Cl}]: 0.30-0.90$ ) in $\mathrm{CrCl}$ $\geq 80 \mathrm{~mL} / \mathrm{min}, 0.85$ (95\% Cl: $0.48-1.21$ ) in $\mathrm{CrCl} 50$ to $79 \mathrm{~mL} / \mathrm{min}$, and 0.33 (95\% Cl: $0.06-1.11)$ in $\mathrm{CrCl} 30$ to $49 \mathrm{~mL} / \mathrm{min}$. Similarly, major bleeding rates were low and numerically increased with declining renal function (0.68/100 patient-years, $95 \% \mathrm{Cl}$ : 0.39-1.03; 0.92, 95\% Cl: 0.58-1.32; and 1.26, 95\% Cl: 0.66-1.97, respectively).

Conclusion In patients with AF, VKA prescriptions increased and dabigatran prescriptions decreased with declining renal function. Rates of stroke and major bleeding in dabigatran patients remained low across the categories of renal impairment.

\section{Introduction}

Some degree of renal impairment is estimated to be present in approximately $35 \%$ of patients with atrial fibrillation (AF) and is associated with increased risk of both thromboembolic and bleeding events. ${ }^{1-3}$ Consequently, oral anticoagulation management is challenging and often requires dose adjustment. Suboptimal use of vitamin K antagonists (VKAs) or non-vitamin $\mathrm{K}$ antagonists (NOACs) increase the risk of stroke and systemic embolism. ${ }^{4-6}$ How renal function affects anticoagulation prescription practice is unclear.

All NOACs undergo some degree of renal clearance. Consequently, diminished renal function could lead to drug accumulation and increase the risk of bleeding complications. Clinical practice guidelines recommend caution regarding NOAC use in patients with renal dysfunction. ${ }^{7,8}$ Rivaroxaban, apixaban, and edoxaban, but not dabigatran, are approved in Europe for use in patients with severe renal impairment (i.e., a creatinine clearance $[\mathrm{CrCl}]$ of $<30 \mathrm{~mL} / \mathrm{min}){ }^{8}$ This differs for the United States, where dabigatran is only contraindicated below a $\mathrm{CrCl}$ of $15 \mathrm{~mL} / \mathrm{min}$ due to the available dose of $75 \mathrm{mg}$ twice daily. ${ }^{9}$ Moreover, in the United States, no contraindications exist for rivaroxaban and apixaban based on renal function. Lower doses, however, are recommended for $\mathrm{CrCl} \leq 50 \mathrm{~mL} / \mathrm{min}$ (rivaroxaban) and serum $\geq 1.5 \mathrm{mg} / \mathrm{dL}$ (apixaban). ${ }^{10,11}$

A meta-analysis demonstrated fewer thromboembolic and major bleeding events in patients with mild or moderate renal impairment $(\mathrm{CrCL}=30-79 \mathrm{~mL} / \mathrm{min})$ treated with NOACs than with VKAs, although there is considerable heterogeneity across studies. ${ }^{12}$ Moreover, the effectiveness and safety of NOACs in patients with a $\mathrm{CrCl}<30 \mathrm{~mL} / \mathrm{min}$ has not been established.

The purposes of this study were to evaluate anticoagulation prescription patterns in relation to baseline renal function for patients with AF enrolled in phase II of the Global Registry on Long-Term Oral Antithrombotic Treatment in Patients with Atrial Fibrillation (GLORIA-AF) study and to describe clinical outcomes over 2 years in patients who received dabigatran etexilate.

\section{Methods}

\section{Patients and Study Design}

The study design and baseline characteristics of patients enrolled in the GLORIA-AF Registry Program have been described previously. ${ }^{13,14}$ In short, GLORIA-AF is an international, prospective, observational and study program, run in three phases, enrolling consecutive adult patients with nonvalvular AF who were newly diagnosed in a variety of clinical settings between 2010 and 2017. The study excluded patients with mechanical heart valves, previous VKA therapy for $>60$ days, AF due to a generally reversible cause, and life expectancy $<1$ year. During phase II of the program (patient enrollment from 2011 to 2014), cross-sectional data were collected, regardless of treatment, and patients prescribed dabigatran were followed for up to 2 years, with visits scheduled around 3, 6, 12, and 24 months. Dabigatran was prescribed at the discretion of treating physicians in available doses (150, 110, and $75 \mathrm{mg}$ twice daily, depending on the country and local label). Patients who took at least one dose of dabigatran were included in the outcome event analysis. Final phase II results have been recently been published. ${ }^{15}$ In the present report, phase II data were evaluated in relation to baseline renal function. GLORIA-AF was a noninterventional study; hence, prescription requirements were not stipulated in the protocol.

\section{Study Aim}

The aims of the study were to evaluate anticoagulation prescription patterns in patients with different $\mathrm{CrCl}$ categories and to describe 2-year incidence rates of stroke, major bleeding, and death for patients treated with dabigatran according to $\mathrm{CrCl}$. The $\mathrm{CrCl}$ was calculated according to Cockcroft-Gault formula: $\mathrm{CrCl}(\mathrm{mL} / \mathrm{min})=(140-$ age $) \times$ weight $(\mathrm{kg}) \times(0.85$ if female $) /$ $(72 \times$ serum creatinine concentration). Renal impairment was categorized according to international guidelines as no impairment $(\mathrm{CrCl} \geq 80 \mathrm{~mL} / \mathrm{min})$, mild impairment $(\mathrm{CrCl}=50$ $79 \mathrm{~mL} / \mathrm{min})$, moderate impairment $(\mathrm{CrCl}=30-49 \mathrm{~mL} / \mathrm{min})$, and severe impairment $(\mathrm{CrCl}<30 \mathrm{~mL} / \mathrm{min}) .{ }^{16,17}$ 


\section{Outcomes}

Only patients taking dabigatran were followed for the occurrence of clinical outcomes. Stroke was defined as the acute onset of a focal neurologic deficit of presumed vascular origin 24 hours or more or resulting in death. Stroke type was categorized as ischemic, hemorrhagic, or uncertain (based on computed tomography or magnetic resonance scanning, or autopsy). Major bleeding was defined according to criteria of the International Society on Thrombosis and Haemostasis. ${ }^{18}$ Deaths were classified as vascular (including bleeding) and nonvascular due to other specified causes (e.g., malignancy) or unknown cause.

\section{Statistical Analysis}

Baseline characteristics of patients were examined by categories of renal function. Continuous variables are presented as the means ( \pm standard deviation $[S D]$ ) or medians (with interquartile range [IQR]) and categoric variables as frequency $(n)$ and percent (\%).

For the derivation of incidence rates of dabigatran outcome incidence rates, the risk period began with treatment initiation and ended with permanent dabigatran discontinuation, which was defined by treatment stop +3 days, substitution of another anticoagulant treatment, or study completion. Incidence rates were calculated based on time to first event of interest. Patients prescribed dabigatran who did not take at least one dose $(n=14)$ were excluded.

To adjust for potential confounding, incidence rates were standardized by HAS-BLED score using two categories, less than 2 or $\geq 2$, and $\mathrm{CHA}_{2} \mathrm{DS}_{2}$-VASc scores using three categories, $<3,3$, and $\geq 4$, for a total of six categories when stratifying by both variables. Standardization was accomplished by obtaining a weighted average of the stratum-specific incidence rates, using weights equal to the total number of patient years for all patients in that stratum. Because only a small number of patients had a $\mathrm{CrCl}<30 \mathrm{~mL} / \mathrm{min}$, rates were not reported for that category. HAS-BLED and $\mathrm{CrCl}$ had noticeable proportions of patients taking dabigatran with missing data (10 and $23 \%$, respectively); multiple imputation using chained equations was applied to address this. ${ }^{19}$ The imputation model was constructed upon 54 clinically relevant baseline patient characteristic variables and the number of imputation is 20 . The CIs of the standardized incidence rates were constructed using the bootstrap method. ${ }^{20}$

\section{Results}

\section{Patient Population}

Baseline characteristics by $\mathrm{CrCl}$ for both the entire population as well as dabigatran users are displayed in - Table 1. Baseline creatinine levels were available for 12,056 of 15,308 eligible patients (79\%). For the entire population, a total of 5,116 of 15,308 patients (33\%) had $\mathrm{CrCl} \geq 80 \mathrm{~mL} / \mathrm{min} ; 4,714$ (31\%) had $\mathrm{CrCl} 50$ to $79 \mathrm{~mL} / \mathrm{min} ; 1,805$ (12\%) had $\mathrm{CrCl} 30$ to $49 \mathrm{~mL} / \mathrm{min}$, 430 (3\%) had $\mathrm{CrCl}<30 \mathrm{~mL} / \mathrm{min}$; and 3,243 (21\%) had missing values. Patients with a $\mathrm{CrCl} \geq 80 \mathrm{~mL} / \mathrm{min}$ were younger ( $63 \pm 10$ years) than those with $\mathrm{CrCl} 50$ to $79 ; 30$ to 49 ; or $<30 \mathrm{~mL} / \mathrm{min}(74 \pm 8,80 \pm 7,80 \pm 11$, respectively), or those with unknown $\mathrm{CrCl}$ values ( $71 \pm 11$ years). Most patients had paroxysmal AF (51-56\%, depending on $\mathrm{CrCl}$ category), followed by persistent (35-37\%) and permanent AF (8-14\%). As expected, the mean $\mathrm{CHA}_{2} \mathrm{DS}_{2}$-VASc score increased with declining renal function, ranging from $2.6(\mathrm{SD}=1.3)$ in patients with a $\mathrm{CrCl} \geq 80 \mathrm{~mL} / \mathrm{min}$ to 4.7 (1.5) in patients with a $\mathrm{CrCl}<30 \mathrm{~mL} / \mathrm{min}$. A similar trend was observed for the mean HAS-BLED score, ranging from $1.1(\mathrm{SD}=0.9)$ to $2.0(1.0)$.

Patients treated with dabigatran had baseline characteristics similar to the overall GLORIA-AF population. Of 4,873 patients prescribed dabigatran, 3,759 (77\%) had creatinine measurements available at baseline. A total of 1,743 of 4,873 (36\%) had $\mathrm{CrCl} \geq 80 \mathrm{~mL} / \mathrm{min}, 1,488$ (31\%) had $\mathrm{CrCl} 50$ to $79 \mathrm{~mL} / \mathrm{min}, 476$ (10\%) had $\mathrm{CrCl} 30$ to $49 \mathrm{~mL} / \mathrm{min}$, and 52 (1\%) had $\mathrm{CrCl}<30 \mathrm{~mL} / \mathrm{min}$.

\section{Anticoagulation Prescription}

At baseline, of all patients with $\mathrm{CrCl} \geq 80 \mathrm{~mL} / \mathrm{min}(n=5,116)$, most were prescribed dabigatran $(n=1,743 ; 34 \%)$ or a VKA $(n=1,534 ; 30 \%)$, followed by rivaroxaban $(n=647 ; 13)$, antiplatelet therapy $(n=592 ; 12 \%)$, no antithrombotic treatment ( $n=389 ; 8 \%)$ and apixaban $(n=188 ; 3.7 \%)$. With declining renal function, prescription rates increased for VKA and decreased for dabigatran (30-47\% and 34-12\%, respectively; - Fig. 1). Of the 52 patients taking dabigatran with $\mathrm{CrCl}<30 \mathrm{~mL} / \mathrm{min}, 41$ (79\%) were treated with the 150 or $110 \mathrm{mg}$ twice daily dosage, and 11 (21\%) received a $75 \mathrm{mg}$ twice-daily dose. Eleven patients receiving the $75 \mathrm{mg}$ twice-daily dose were all located in the United States. Among all dabigatran patients, $0.9 \%(n=41)$ received dabigatran 150 and $110 \mathrm{mg}$ BID and had a $\mathrm{CrCl}<30 \mathrm{~mL} / \mathrm{min}$, constituting a contraindication. Prescription rates for other NOACs were similar across renal function strata (9.3-13\% for rivaroxaban and 3.5-6.5\% for apixaban, depending on $\mathrm{CrCl}$ ). As renal function decreased, prescription of other NOAC standard doses decreased and use of low doses increased, although contraindications due to $\mathrm{CrCl}$ were not further assessed. The dabigatran standard dose ( $150 \mathrm{mg}$ twice daily) was prescribed more frequently in patients with normal renal function (72\%) than for those with $\mathrm{CrCl} 50$ to 79 (45\%) or 30 to $49 \mathrm{~mL} / \mathrm{min}$ (20\%) (-Table 2). The prescription rate of antiplatelet or no treatment was consistent across the renal function strata (19-23\%, depending on $\mathrm{CrCl}$ ).

\section{Clinical Outcomes}

Clinical outcomes in dabigatran-treated patients are shown in - Table 3. The standardized incidence rates for stroke were $0.58 / 100$ patient-years (95\% confidence interval $[\mathrm{CI}]: 0.30-0.90$ ) for $\mathrm{CrCl} \geq 80 \mathrm{~mL} / \mathrm{min}, 0.85 / 100$ patient-years (95\% CI: 0.51-1.2) for $\mathrm{CrCl} 50$ to $79 \mathrm{~mL} / \mathrm{min}$, and $0.33 / 100$ patient-years $(95 \% \mathrm{CI}$ : 0.06-1.1) for $\mathrm{CrCl} 30$ to $49 \mathrm{~mL} / \mathrm{min}$. The incidence rates for major bleeding were $0.68 / 100$ patient-years ( $95 \% \mathrm{Cl}: 0.39-1.0$ ) for $\mathrm{CrCl}$ $\geq 80 \mathrm{~mL} / \mathrm{min}, 0.92 / 100$ patient-years (95\% Cl: $0.58-1.3$ ) for $\mathrm{CrCl}$ 50 to $79 \mathrm{~mL} / \mathrm{min}$, and 1.26 (95\% CI: $0.66-2.0$ ) for $\mathrm{CrCl} 30$ to $49 \mathrm{~mL} / \mathrm{min}$. The rates for all-cause death were highest in patients with a $\mathrm{CrCl} 30$ to $49 \mathrm{~mL} / \mathrm{min}$ (4.5/100 patient-years; 95\% Cl: 3.1-6.3), followed by patients with $\mathrm{CrCl} 50$ to $79 \mathrm{~mL} / \mathrm{min}$ (2.6/100 patient-years; $95 \% \mathrm{CI}: 2.0-3.3$ ) and patients with $\mathrm{CrCl}$ $\geq 80 \mathrm{~mL} / \mathrm{min}$ (1.6/100 patient-years; $95 \% \mathrm{CI}: 1.1-2.2$ ). 


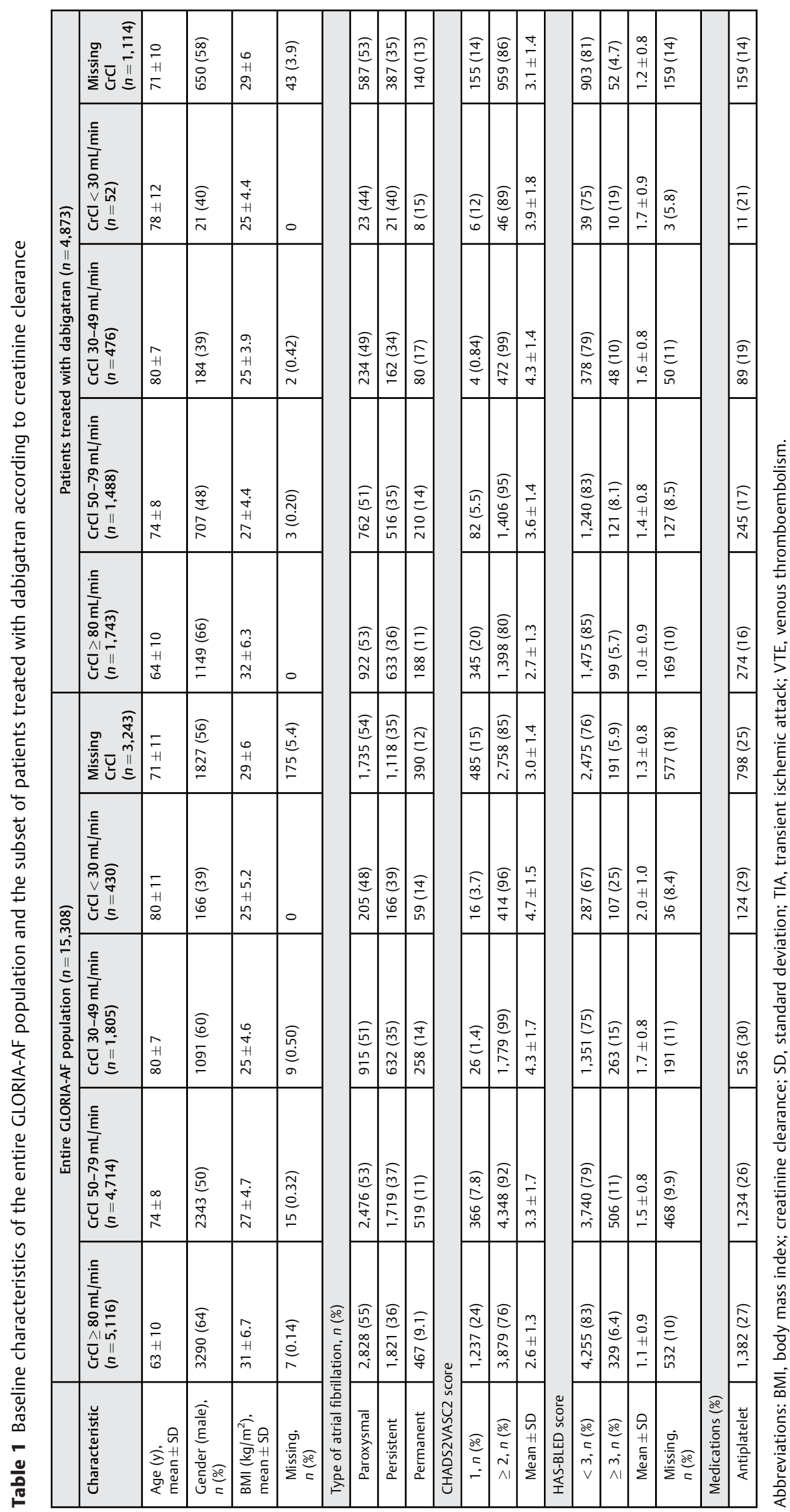




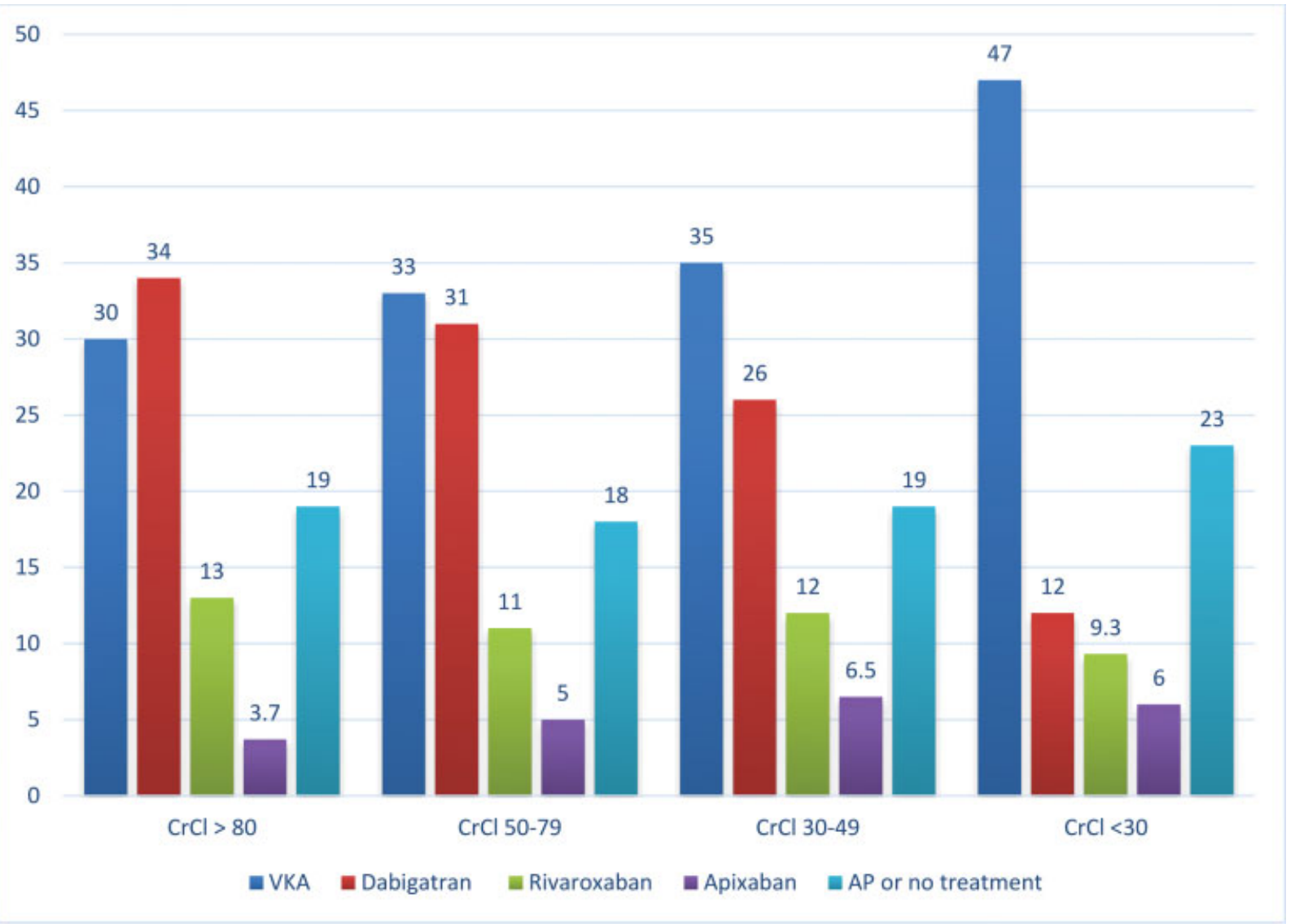

Fig. 1 Antithrombotic prescription patterns according to $\mathrm{CrCl}$ in GLORIA-AF. Numbers are percentages. $\mathrm{CrCl}$ in $\mathrm{mL} / \mathrm{min}$. AP, antiplatelet therapy; $\mathrm{CrCl}$, creatinine clearance; VKA, vitamin $\mathrm{K}$ antagonist.

\section{Discussion}

The first main finding of this large global prospective study is that VKA prescription increased and dabigatran prescription decreased with declining renal function. No clear trend could be observed for the prescription of other NOACs and antiplatelet/ no treatment groups. Second, less than $1 \%$ of dabigatran users were prescribed the contraindicated 150 and $110 \mathrm{mg}$ twicedaily dosages when their $\mathrm{CrCl}$ was $<30 \mathrm{~mL} / \mathrm{min}$. Third, among dabigatran users, the estimated rates of stroke and major bleeding were low across all $\mathrm{CrCl}$ categories.

Consistent with the EURObservational Research Program: the Heart Failure Pilot Survey on patients with AF (EORP-AF Pilot), nearly $60 \%$ of enrolled patients had a $\mathrm{CrCl} 30$ to $79 \mathrm{~mL} / \mathrm{min}$ and $4 \%$ had a $\mathrm{CrCl}<30 \mathrm{~mL} / \mathrm{min} .{ }^{21}$ Patients with declining renal function were older and had a higher risk of stroke (CHA2DS2-VASc score $\geq 2$ ) and bleeding risk (HAS$B L E D \geq 3$ ). This might have led to a decrease in dabigatran prescriptions, although both the 150 and $110 \mathrm{mg}$ twice daily doses have been found to be safe in patients with a $\mathrm{CrCl} 30$ to $79 \mathrm{~mL} / \mathrm{min}^{22,23}$ Conversely, VKA prescriptions increased, with the highest incidence of $47 \%$ in patients with a $\mathrm{CrCl}$ $<30 \mathrm{~mL} / \mathrm{min}$. Consistent with other studies, the use of the dabigatran 150 and $110 \mathrm{mg}$ twice daily doses in patients with a $\mathrm{CrCl}<30 \mathrm{~mL} / \mathrm{min}$ was less than $1 \%$, indicating that contraindicated dabigatran use is rare in clinical practice. ${ }^{24,25}$ For other NOACs, similar prescription rates were observed across
$\mathrm{CrCl}$ groups, which is probably related to label differences (i.e., $<15 \mathrm{~mL} / \mathrm{min}$ for rivaroxaban, edoxaban, and apixaban in the European Union, and no contraindications for rivaroxaban and apixaban in the United States). Moreover, the enrollment period must be taken into account. As dabigatran was the only NOAC approved in the European Union during the first year of study enrollment, higher number of dabigatran prescriptions are included in this assessed cohort as compared with other NOACs.

We found low rates of stroke (rate estimates range from 0.46 to $0.96 / 100$ patient-years) and major bleeding (rate estimates range from 0.72 to 2/100 patient-years) across all $\mathrm{CrCl}$ categories with wide and overlapping confidence intervals. These rates are consistent with those observed in the EORP-AF Pilot registry in which the 1-year rates of stroke and major bleeding were similar across different renal groups. ${ }^{21}$ However, although not directly comparable, the RE-LY trial reported increasing stroke, systemic embolism, and major bleeding incidences with declining renal function, with highest risk estimates in patients with a $\mathrm{CrCL} 30$ to $49 \mathrm{~mL} / \mathrm{min}$ and lowest in those with normal renal function, including patients using VKA. ${ }^{23,26}$ Importantly, the RE-LY study was a randomized trial without specified dose reductions and thereby evaluated both dabigatran 150 and $110 \mathrm{mg}$ twice daily doses, independent of $\mathrm{CrCl}$. Conversely, in our study, dosing was individualized based on patient characteristics and physician and/or patient preferences, including the 


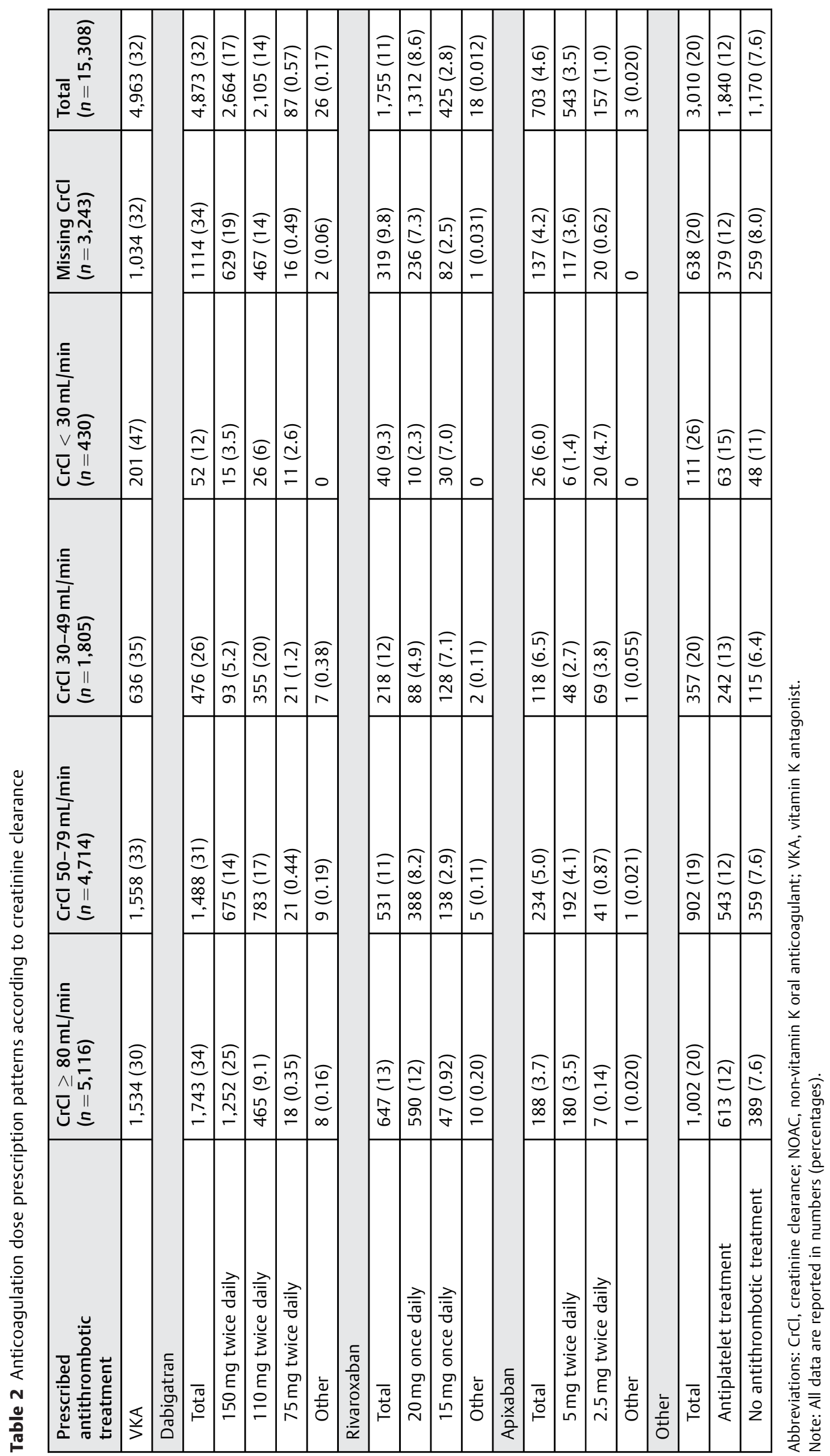


Table 3 Crude and standardized incidence rates of dabigatran patients stratified by creatinine clearance

\begin{tabular}{|c|c|c|c|c|c|c|}
\hline \multirow[b]{2}{*}{ Event } & \multicolumn{3}{|c|}{$\begin{array}{l}\text { Crude incidence rates, } \\
\text { per } 100 \text { patient-years }(95 \% \mathrm{Cl})\end{array}$} & \multicolumn{3}{|c|}{$\begin{array}{l}\text { Standardized incidence rates, } \\
\text { per } 100 \text { patient-years }(95 \% \mathrm{Cl})\end{array}$} \\
\hline & $\begin{array}{l}\mathrm{CrCl} \geq 80 \\
(n=1,738)\end{array}$ & $\begin{array}{l}\mathrm{CrCl} 50-79 \\
(n=1,483)\end{array}$ & $\begin{array}{l}\mathrm{CrCl} 30-49 \\
(n=475)\end{array}$ & $\mathrm{CrCl} \geq 80$ & $\mathrm{CrCl} 50-79$ & $\mathrm{CrCl} 30-49$ \\
\hline \multicolumn{7}{|l|}{ Stroke } \\
\hline Stroke ${ }^{a}$ & $\begin{array}{l}0.53 \\
(0.29-0.89)\end{array}$ & $\begin{array}{l}0.96 \\
(0.6-1.5)\end{array}$ & $\begin{array}{l}0.46 \\
(0.1-1.4)\end{array}$ & $\begin{array}{l}0.58 \\
(0.30-0.90)\end{array}$ & $\begin{array}{l}0.85 \\
(0.51-1.2)\end{array}$ & $\begin{array}{l}0.33 \\
(0.06-1.1)\end{array}$ \\
\hline $\begin{array}{l}\text { Ischemic or } \\
\text { hemorrhagic } \\
\text { stroke }\end{array}$ & $\begin{array}{l}0.46 \\
(0.24-0.8)\end{array}$ & $\begin{array}{l}0.73 \\
(0.42-1.2)\end{array}$ & $\begin{array}{l}0.46 \\
(0.1-1.4)\end{array}$ & $\begin{array}{l}0.47 \\
(0.23-0.75)\end{array}$ & $\begin{array}{l}0.59 \\
(0.33-0.88)\end{array}$ & $\begin{array}{l}0.23 \\
(0-0.53)\end{array}$ \\
\hline \multicolumn{7}{|l|}{ Death } \\
\hline All cause & $\begin{array}{l}1.2 \\
(0.83-1.7)\end{array}$ & $\begin{array}{l}2.7 \\
(2.1-3.5)\end{array}$ & $\begin{array}{l}5.4 \\
(3.8-7.5)\end{array}$ & $\begin{array}{l}1.6 \\
(1.1-2.2)\end{array}$ & $\begin{array}{l}2.6 \\
(2.0-3.3)\end{array}$ & $\begin{array}{l}4.5 \\
(3.1-6.3)\end{array}$ \\
\hline Vascular & $\begin{array}{l}0.49 \\
(0.26-0.84)\end{array}$ & $\begin{array}{l}0.78 \\
(0.45-1.3)\end{array}$ & $\begin{array}{l}1.7 \\
(0.85-3.0)\end{array}$ & $\begin{array}{l}0.69 \\
(0.37-1.1)\end{array}$ & $\begin{array}{l}0.81 \\
(0.49-1.2)\end{array}$ & $\begin{array}{l}1.8 \\
(0.81-3.4)\end{array}$ \\
\hline Non-vascular & $\begin{array}{l}0.45 \\
(0.23-0.79)\end{array}$ & $\begin{array}{l}1.3 \\
(0.85-1.9)\end{array}$ & $\begin{array}{l}2.2 \\
(1.2-3.6)\end{array}$ & $\begin{array}{l}0.59 \\
(0.30-0.96)\end{array}$ & $\begin{array}{l}1.2 \\
(0.74-1.6)\end{array}$ & $\begin{array}{l}1.5 \\
(0.77-2.3)\end{array}$ \\
\hline \multicolumn{7}{|l|}{ Major bleeding } \\
\hline All major bleeding & $\begin{array}{l}0.72 \\
(0.43-1.1)\end{array}$ & $\begin{array}{l}1.1 \\
(0.67-1.6)\end{array}$ & $\begin{array}{l}2 \\
(1.1-3.4)\end{array}$ & $\begin{array}{l}0.68 \\
(0.39-1.0)\end{array}$ & $\begin{array}{l}0.92 \\
(0.58-1.3)\end{array}$ & $\begin{array}{l}1.26 \\
(0.66-2.0)\end{array}$ \\
\hline Life-threatening & $\begin{array}{l}0.3 \\
(0.13-0.6)\end{array}$ & $\begin{array}{l}0.5 \\
(0.25-0.9)\end{array}$ & $\begin{array}{l}0.93 \\
(0.34-2.0)\end{array}$ & $\begin{array}{l}0.29 \\
(0.11-0.53)\end{array}$ & $\begin{array}{l}0.45 \\
(0.22-0.72)\end{array}$ & $\begin{array}{l}0.54 \\
(0.19-1.0)\end{array}$ \\
\hline
\end{tabular}

Abbreviations: $\mathrm{Cl}$, confidence interval; $\mathrm{CrCl}$, creatinine clearance.

Note: Patients with $\mathrm{CrCl}<30 \mathrm{~mL} / \mathrm{min}$ were omitted from this analysis due to low numbers. Standardized incidence rates were calculated with all missing HAS-BLED and $\mathrm{CrCl}$ values imputed.

ancludes hemorrhagic, ischemic strokes, and strokes of unknown origin.

perceived bleeding risk. Therefore, our findings emphasize that dabigatran can safely be used in patients with mild-tomoderate impairment. Of note, in the ongoing phase III of GLORIA-AF follow-up data will be collected from VKAtreated patients, allowing for future comparison of safety and effectiveness. ${ }^{13}$

\section{Limitations}

This study has several limitations. First, $\mathrm{CrCl}$ values were missing in $21 \%$ of patients and were imputed for the outcome analyses. Second, due to broad inclusion of many centers and countries in this global registry, slight differences in NOAC labels existed regarding $\mathrm{CrCl}$, which might have influenced the prescription pattern. Third, while we standardized for CHADS-VASc and HAS-BLED scores, other differences in baseline characteristics $\mathrm{CrCl}$ groups may not adequately have been captured. Finally, we assessed renal function at baseline and did not assess changes in renal function over the follow-up period.

In conclusion, in contrast to VKA, dabigatran prescription decreased with declining renal function and was rare in patients with severe renal impairment. Further, in dabigatran-treated patients, the estimated rates of stroke and major bleeding were low across the categories of renal impairment.

Note

This study is registered with ClinicalTrials.gov with identifier no. NCT01468701 (http://www.clinicaltrials.gov).
Funding

This study was funded by Boehringer Ingelheim $\mathrm{GmbH}$.

Conflict of Interest

S.J.V declares no conflict of interest. H.C.D. has received honoraria for participation in clinical trials, contribution to advisory boards or oral presentations from Abbott, Allergan, AstraZeneca, Bayer Vital, Boehringer Ingelheim, Bristol-Myers Squibb, Covidien, Daiichi-Sankyo, GlaxoSmithKline, Janssen-Cilag, Johnson \& Johnson, Knoll, Lilly, Merck Sharp \& Dohme, Medtronic, Novartis, Pfizer, Sanofi-Aventis, Servier, St Jude, and WebMD Global. The Department of Neurology at the University DuisburgEssen received research grants from the German Research Council (DFG), the German Ministry of Education and Research (BMBF), the European Union, the National Institutes of Health $(\mathrm{NIH})$, the Bertelsmann Foundation, and the Heinz-Nixdorf Foundation. S.J.D. has received consultancy fees for serving as a steering committee member for Boehringer Ingelheim. He also holds research grants from Abbott (St Jude Medical). J.H. is currently conducting research sponsored by Boehringer Ingelheim as a member of the Executive Steering Committee for the GLORIA-AF Registry, and has received consulting fees from Bayer HealthCare, Janssen-Ortho-McNeil, and Pfizer for advisory activities involving the development of anticoagulant drugs. C.H.M. has received honoraria for presentations, as well as research grants from AstraZeneca, Bayer 
HealthCare, Boehringer Ingelheim, Bristol-Myers Squibb, Johnson \& Johnson, and Pfizer. K.J.R. is an employee of RTI Health Solutions, an independent nonprofit research organization that works with government agencies and pharmaceutical companies. C.T., M.P., K.Z., L.R.F., and S.L. are employees of Boehringer Ingelheim. G.Y.H.L. has been a consultant for Bayer/Janssen, Boehringer Ingelheim, Bristol-Myers Squibb/Pfizer, Daiichi-Sankyo, Medtronic, Novartis, and Verseon; and speaker for Bayer, Boehringer Ingelheim, Bristol-Myers Squibb/Pfizer, Daiichi-Sankyo, and Medtronic. M.V.H. has received honoraria for presentations and research grants from Actelion Pharmaceuticals, Bayer HealthCare, Boehringer Ingelheim, GlaxoSmithKline, and Pfizer.

\section{References}

1 Bonde AN, Lip GY, Kamper AL, et al. Net clinical benefit of antithrombotic therapy in patients with atrial fibrillation and chronic kidney disease: a nationwide observational cohort study. J Am Coll Cardiol 2014;64(23):2471-2482

2 Kooiman J, van de Peppel WR, van der Meer FJ, Huisman MV. Incidence of chronic kidney disease in patients with atrial fibrillation and its relevance for prescribing new oral antithrombotic drugs. J Thromb Haemost 2011;9(08):1652-1653

3 Olesen JB, Lip GY, Kamper AL, et al. Stroke and bleeding in atrial fibrillation with chronic kidney disease. N Engl J Med 2012;367 (07):625-635

4 Birman-Deych E, Radford MJ, Nilasena DS, Gage BF. Use and effectiveness of warfarin in Medicare beneficiaries with atrial fibrillation. Stroke 2006;37(04):1070-1074

5 Larock AS, Mullier F, Sennesael AL, et al. Appropriateness of prescribing dabigatran etexilate and rivaroxaban in patients with nonvalvular atrial fibrillation: a prospective study. Ann Pharmacother 2014;48(10):1258-1268

6 Wilke T, Groth A, Mueller S, et al. Oral anticoagulation use by patients with atrial fibrillation in Germany. Adherence to guidelines, causes of anticoagulation under-use and its clinical outcomes, based on claims-data of 183,448 patients. Thromb Haemost 2012;107(06):1053-1065

7 January CT, Wann LS, Calkins H, et al. 2019 AHA/ACC/HRS Focused Update of the 2014 AHA/ACC/HRS Guideline for the Management of Patients With Atrial Fibrillation: a Report of the American College of Cardiology/American Heart Association Task Force on Clinical Practice Guidelines and the Heart Rhythm Society in Collaboration With the Society of Thoracic Surgeons. Circulation 2019;140(02):e125-e151

8 Steffel J, Verhamme P, Potpara TS, et al;ESC Scientific Document Group. The 2018 European Heart Rhythm Association Practical Guide on the use of non-vitamin K antagonist oral anticoagulants in patients with atrial fibrillation. Eur Heart J 2018;39(16):1330-1393

9 Food and Drug Administration (FDA) 2015Prescribing Information, Pradaxa. Accessed June 2020 at: https://www.accessdata. fda.gov/drugsatfda_docs/label/2015/022512s028lbl.pdf

10 Food and Drug Administration (FDA) 2012Prescribing Information, Eliquis. Accessed June 2020 at: https://www.accessdata. fda.gov/drugsatfda_docs/label/2012/202155s000lbl.pdf

11 Food and Drug Administration (FDA) 2020Prescribing Information, Xarelto. Accessed June 2020 at: https://www.accessdata. fda.gov/drugsatfda_docs/label/2012/202155s000lbl.pdf

12 Raccah BH, Perlman A, Danenberg HD, Pollak A, Muszkat M, Matok I. Major bleeding and hemorrhagic stroke with direct oral anticoagulants in patients with renal failure: systematic review and meta-analysis of randomized trials. Chest 2016;149 (06):1516-1524

13 Huisman MV, Lip GY, Diener HC, et al. Design and rationale of Global Registry on Long-Term Oral Antithrombotic Treatment in Patients with Atrial Fibrillation: a global registry program on long-term oral antithrombotic treatment in patients with atrial fibrillation. Am Heart J 2014;167(03):329-334

14 Huisman MV, Rothman KJ, Paquette M, et al;GLORIA-AF Investigators. Antithrombotic treatment patterns in patients with newly diagnosed nonvalvular atrial fibrillation: the GLORIA-AF Registry, Phase II. Am J Med 2015;128(12):1306-13.e1

15 Mazurek M, Teutsch C, Diener HC, et al;GLORIA-AF Investigators. Safety and effectiveness of dabigatran at 2 years: final outcomes from phase II of the GLORIA-AF registry program. Am Heart J 2019;218:123-127

16 January CT, Wann LS, Alpert JS, et al;ACC/AHA Task Force Members. $2014 \mathrm{AHA} / \mathrm{ACC} / \mathrm{HRS}$ guideline for the management of patients with atrial fibrillation: executive summary: a report of the American College of Cardiology/American Heart Association Task Force on practice guidelines and the Heart Rhythm Society. Circulation 2014;130(23):2071-2104

17 Kirchhof P, Benussi S, Kotecha D, et al;ESC Scientific Document Group. 2016 ESC Guidelines for the management of atrial fibrillation developed in collaboration with EACTS. Eur Heart J 2016;37 (38):2893-2962

18 Schulman S, Kearon CSubcommittee on Control of Anticoagulation of the Scientific and Standardization Committee of the International Society on Thrombosis and Haemostasis. Definition of major bleeding in clinical investigations of antihemostatic medicinal products in non-surgical patients. J Thromb Haemost 2005;3(04):692-694

19 White IR, Royston P, Wood AM. Multiple imputation using chained equations: Issues and guidance for practice. Stat Med 2011;30(04):377-399

20 Schomaker M, Heumann C. Bootstrap inference when using multiple imputation. Stat Med 2018;37(14):2252-2266

21 Boriani G, Laroche C, Diemberger I, et al. Glomerular filtration rate in patients with atrial fibrillation and 1-year outcomes. Sci Rep 2016;6:30271

22 Eikelboom JW, Wallentin L, Connolly SJ, et al. Risk of bleeding with 2 doses of dabigatran compared with warfarin in older and younger patients with atrial fibrillation: an analysis of the randomized evaluation of long-term anticoagulant therapy (RE-LY) trial. Circulation 2011;123(21):2363-2372

23 Hijazi Z, Hohnloser SH, Oldgren J, et al. Efficacy and safety of dabigatran compared with warfarin in relation to baseline renal function in patients with atrial fibrillation: a RE-LY (randomized evaluation of long-term anticoagulation therapy) trial analysis. Circulation 2014;129(09):961-970

24 Ramagopalan SV, Stamp E, Sammon CJ, et al. Renal function and oral anticoagulant treatment of incident non-valvular atrial fibrillation: a retrospective study. Future Cardiol 2019;15(04): 301-309

25 Steinberg BA, Holmes DN, Piccini JP, et al;Outcomes Registry for Better Informed Treatment of Atrial Fibrillation (ORBIT-AF) Investigators and Patients. Early adoption of dabigatran and its dosing in US patients with atrial fibrillation: results from the outcomes registry for better informed treatment of atrial fibrillation. J Am Heart Assoc 2013;2(06):e000535

26 Connolly SJ, Ezekowitz MD, Yusuf S, et al;RE-LY Steering Committee and Investigators. Dabigatran versus warfarin in patients with atrial fibrillation. N Engl J Med 2009;361(12):1139-1151 